\title{
Effects of fisheries management on local ecological knowledge
}

\author{
Emily R. Farr $^{1}$, $\underline{\text { Joshua S. Stoll }}^{1,2}$ and Christine M. Beitl ${ }^{3}$
}

\begin{abstract}
Local ecological knowledge, or the collective perceptions held by a particular group about their environment, results from the transmission of cultural knowledge from one generation to the next, combined with regular and persistent interactions between individuals and the biophysical environment. Management systems that limit access to certain natural resources likely have an effect on the quality of that knowledge. We explore the distribution of local ecological knowledge as it corresponds to different types of fishing activities and experience among fishermen in the eastern Gulf of Maine. We use a network approach to analyze cognitive maps of the ecosystem structure and dynamics described by fishermen during in-depth, open-ended interviews. The interviews reveal unique perspectives on complex interactions between species and their habitat, providing insights about local fluctuations in water temperature and weather patterns, predator-prey dynamics and interspecies competition, with a particular focus on species of commercial interest. We find a significant positive relationship between individuals' diversification in fisheries and the scope of their knowledge. The preliminary findings suggest that fishermen with diversified fishing portfolios interact with a broader range of components in the system, resulting in a more holistic understanding of the marine environment and its dynamics. Because regulatory measures in fisheries management increasingly constrain the ability of individuals to enter diverse fisheries, these findings have significant implications for sustainability and understanding the role that institutions play in shaping local ecological knowledge more generally. A more systematic investigation of how institutional constraints affect the distribution of local ecological knowledge would be well-positioned to inform ecosystem-based approaches in fisheries management.
\end{abstract}

Key Words: access; cognitive maps; diversification; fisheries management; Gulf of Maine; local ecological knowledge; network analysis

\section{INTRODUCTION}

The role that local ecological knowledge (LEK) can or should play in informing natural resource governance is the subject of ongoing debate that stems from divergent views about the accuracy and applicability of LEK to management. LEK refers to a form of experiential information about the natural environment that is accumulated by interacting with it on a regular basis (Berkes et al. 2000, Murray et al. 2006) and that is often culturally transmitted from one generation to the next or horizontally through socialization (Ruddle 1994). Recent LEK research has been largely concerned with questions about how knowledge can inform management, placing less emphasis on the inverse relationship. Numerous case studies, for example, document the successful integration of fishermen's LEK into management, including those of the softshell clam (Hanna 1998) and lobster (Acheson 2003) fisheries in Maine, prawn fishery in South Australia (Hollamby et al. 2010), and small-scale and mixed species fisheries in Puerto Rico (García-Quijano 2007). Similar case studies also describe how LEK has aided in the creation of marine protected areas (Aswani and Lauer 2006), supported ecosystem-based management (Olsson and Folke 2001, Wondolleck and Yaffee 2017), and informed adaption strategies to changes in the ecosystem triggered by drivers such as climate change and overfishing (Berkes et al. 2000, Carothers et al. 2014). Collectively, these studies support the view that marine resource users' knowledge can complement scientific assessments and monitoring programs by providing fine-scale information that is tuned to the particulars of specific places.

Failure to integrate fishermen's knowledge about ecological processes into management decisions has, in some cases, meant that key insights about fishery resources were missed, resulting in unwanted management outcomes (Finlayson 1994, Johannes et al. 2000). For example, work by Ames (2004) used data gathered through interviews with retired groundfish fishermen to identify discrete subpopulations of cod in the Gulf of Maine with distinct migration corridors and spawning grounds. Management of the stock at a broad geographic scale did not account for this complex metapopulation structure, making the cod vulnerable to localized extirpations. This scale mismatch between management approaches and ecosystem dynamics suggests a need for novel approaches to the governance of marine resources that account for multiple sources of information.

The literature comparing LEK to science-based knowledge, however, is less conclusive (Silvano and Valbo-Jørgensen 2008), raising questions about the utility of LEK to management and lending support to critics' skepticism (Moller et al. 2004, Murray et al. 2005). For example, Moller et al. (2004), describe the problem of nonrandom population sampling, whereby harvesters target "hot spots" during times of low species abundance. Focusing fishing efforts on these high-density areas may mean fishermen are unaware of the overall distribution of the target species' population that is picked up by the broader scale of randomized scientific assessments. Other researchers have responded to such critiques with three primary points of clarification about the utility and limitations of LEK. First, the scale of observations between LEK and science-based knowledge is often misaligned, with LEK generally acquired at longer temporal and smaller spatial scales (Gagnon and Berteaux 2009, Wohling 2009). Second, knowledge of a resource does not necessarily imply cultural importance or conservation ethic (Casagrande 2004). Studies of LEK should exercise caution in the design of data collection instruments, interpretation, and

${ }^{1}$ Maine Center for Coastal Fisheries, ${ }^{2}$ School of Marine Sciences, University of Maine, ${ }^{3}$ Department of Anthropology, University of Maine 
inferences. Finally, many researchers recognize LEK as a more holistic and relational form of knowledge (García-Quijano 2007), which places a greater emphasis on processes, feedbacks, and relationships between people and ecology than science-based knowledge (Walsh et al. 2013) that tends to be taxonomic and narrower in scope. When decontextualized to fit into a scientific frame of reference, this complexity is often lost or distorted and the value of LEK is diminished (Nadasdy 1999, 2003). These counterpoints and counter counterpoints fuel the debate surrounding the relevance of LEK to management, leaving aside the role that management systems have in shaping knowledge production.

Although the debate surrounding the utility of LEK to management is unlikely to be settled in the short term, we posit that greater attention to the process of knowledge production, as well as factors shaping the heterogeneous distribution of knowledge, will prove useful in bridging LEK and other forms of science to inform management practice. The study of LEK potentially offers the opportunity for two-way learning and coproduction of knowledge. Fishermen learn technical language used by biologists and stock assessment scientists, while scientists learn fine-scale ecological interactions and information about the context that may not be captured in conventional scientific sampling methods. Systematic analyses of LEK can help contextualize knowledge, facilitate dialogue, and elucidate shared values between scientists, fishermen, and managers (Paolisso 2002). This would be of particular interest to proponents of ecosystem-based approaches to fisheries management, a paradigm shift that is attentive to the physical, biological, economic, and social interactions in the ecosystem (Pikitch et al. 2004), and recognizes the potential for LEK to complement and enhance scientific knowledge (Ommer et al. 2012, García-Quijano and Pizzini 2015). Both qualitative and quantitative understandings of the factors that shape how fishermen conceive their marine environment would contribute to a more contextualized, place-based understanding of ecological relationships and processes.

In the case of fisheries, a range of factors influence how fishermen interact with the marine environment, including length of fishing experience (Pauly 1995), scale of operation (Crona 2006), gear type (Ames 2002), and fishing portfolios (García-Quijano 2006, Garavito-Bermúdez et al. 2016, Stoll et al. 2016). Each of these factors affect the "pieces" of the ecosystem that resource users interact with, which in turn influences the information that they acquire. Increasingly, fishermen's decisions are also influenced by management systems that have been created to address specific problems in particular fisheries, in part, by limiting access to those fisheries by creating fishing licenses in order to prevent overexploitation of stocks (Stoll et al. 2016). As natural resources around the world become increasingly managed, and these management systems constrain the way fishermen interact with the marine environment, understanding how these institutions affect LEK becomes increasingly important for setting expectations for the kind of knowledge that LEK can contribute to management.

In this paper, we describe fishermen's knowledge of the marine ecosystem in a region of Maine where fishermen have a long history of informing management, and examine the relationship between LEK and fishing access. Here, we use fisherman as a gender-neutral term because it is the one used most commonly by both men and women who fish in Maine, including all of the individuals we interviewed. Maine is an appropriate context to test hypotheses about the role of fisheries management on LEK because the fishing fleet has historically participated in a wide range of fisheries and individuals have vastly different fishing portfolios (Stoll et al. 2017). Fishermen gain access to fisheries by acquiring and maintaining fishing licenses for particular species; however, access to nearly all fisheries is limited, which makes it difficult (and in some cases impossible) for a fisherman to participate in a fishery if s/he does not already hold a license because of restrictions that have been put on the fisheries (Stoll et al. 2016).

We use a multilevel network approach to explore the heterogeneity in LEK among fishermen in the eastern Gulf of Maine. Specifically, we analyze cognitive maps of the ecosystem structure and dynamics described by fishermen during in-depth, openended interviews. Cognitive maps are qualitative models of a system that are composed of variables (hereafter, nodes) and the causal relationships between those nodes (hereafter, edges), and can be used to produce graphical representations of knowledge about a system, i.e., networks (Hmelo-Silver and Pfeffer 2004, Özesmi and Özesmi 2004). Similar approaches have been used to explore variability in stakeholders' perceptions of marine food webs (Stier et al. 2017), describe fishermen's ecological, social, and historical knowledge about the health of a fish stock (Curtin and Hammit 2012), model the organization of individual and community knowledge about fishery systems (Gray et al. 2012), and investigate the drivers of ecological complexity (GaravitoBermúdez et al. 2016) and the emergence of leadership among fishers (Stoll 2017). Researchers have systematically used cognitive maps to examine fishermen's knowledge about specific food webs (Gray et al. 2012, Stier et al. 2017), within discrete boundaries like individual lakes or fishing villages (Olsson and Folke 2001, Crona 2006, Garavito-Bermúdez et al. 2016), and about particular fisheries (Curtin and Hammit 2012). Here, we do not limit our observations to a single fishery, community, or food web, but rather examine the breadth and distribution of knowledge held by fishermen across a relatively broad space and about multiple commercially important species. In so doing, we are able to address questions about patterns in LEK at both individual and group levels with special attention to the influence of management, which currently constrains fishermen's access to diversified portfolios, thereby limiting their capacity to contribute their knowledge to management.

\section{METHODS}

\section{Soliciting local ecological knowledge}

We conducted in-depth, semistructured interviews with 17 commercial fishermen in 12 towns in eastern Maine who participate or have participated in a combined total of 18 fisheries. To understand the relationship between fishing access and the production of ecological knowledge, interviews were conducted with fishermen with experience in nearly all of the commercially important fisheries in Maine, including the lobster (Homarus americanus), elver (Anguilla rostrata), herring (Clupea harengus), softshell clam (Mya arenaria), groundfish, urchin (Strongylocentrotus droebachiensis), and scallop (Placopecten magellanicus) fisheries. 
Our research focused on fishermen in Washington and Hancock Counties because this is an area where fishing is a particularly important part of the coastal economy (Colburn et al. 2010). Initial interviewees $(n=7)$ were referred to us by the Maine Center for Coastal Fisheries, a nonprofit based in the region with existing rapport with local fishing communities. Recommended fishermen had previously participated in research or management activities and were comfortable being interviewed. We identified the remaining interviewees using a snowball sampling approach by asking each participant to recommend other respected or accomplished fishermen (Berg 2004). Interviews occurred in person, at a place of the fisherman's choosing, and lasted between 45 minutes and 1.5 hours.

Rather than focus on fishermen with particular skillsets or experiences or in a specific geographic area, interviews aimed to gather perspectives reflecting a broad range of characteristics, including age, geography, fisheries license portfolio, availability, and willingness to participate in the project. Fishermen ranged in age from 25 to 71 and participated in one to nine fisheries, accounting for both past and present participation. These fishermen have 15 to 67 years of experience and live and work throughout the region. The interview process and interpretation of the results were also informed by participant observation at fisheries management meetings, on commercial fishing trips, and by living in one of the fishing communities that was a part of this study.

Interviews were guided by a series of open-ended questions about commercial fishing practices, habitat dynamics, ecological and biophysical parameters affecting target species, food web relationships, and environmental and socioeconomic change. For individuals who have participated in multiple fisheries, we asked them to discuss fisheries in which they feel the most knowledgeable or accomplished. Nautical charts were an excellent tool to facilitate free-flowing conversations that were relevant for in-depth understanding of spatial and temporal dynamics of system properties and relationships. This prompted many research participants to recall specific kinds of detailed information about the marine environment that form part of the larger picture. This included information about the broader social and economic context of fishing, such as changing technology, markets and management institutions. Each interview was recorded, transcribed, and coded inductively using the qualitative analysis software NVivo that allowed for the continual refinement of codes based on emergent themes from interview data.

\section{Linking LEK to fisheries management through fisheries participation}

We asked each fisherman to identify all of the fisheries in which $\mathrm{s} /$ he has participated over the course of his or her lifetime, then cross-referenced those lists with fisheries licensing data from the Maine Department of Marine Resources to determine past and present participation for each individual following the methods described by Stoll et al. (2017). Some fishermen identified fisheries in which they were a crew member for another licensed fisherman, which we counted toward their participation, though they were not the license holders. This combination of license and interview data allowed us to incorporate both formal and informal fisheries participation in our analyses.

\section{Network analysis of cognitive maps}

Multigraphs consider multiple types of relationships, or edges, between the components of a network. In complex systems, these different processes and relationships can facilitate understanding of system structure and dynamics (Shafie 2015). As such, a multigraph approach allows for a more holistic examination of ecosystems, which are composed of numerous ecological and biophysical components with differing types of relationships, e.g., predation, habitat. We simultaneously examined two network levels: (1) fishermen's connection to marine resources (via their past and/or present participation in fisheries) and (2) fishermen's knowledge of how ecosystem components interact. Our use of multilevel and multigraph cognitive maps enabled us to identify and integrate the diverse knowledge that fishermen have about the ecosystem (Gray et al. 2012, Ommer et al. 2012). Cognitive maps provide a framework for analyzing relationships between variables, while our use of social network analyses on those maps allowed us to systematically examine how human connections to marine resources shape ecological knowledge. This novel approach was informed by a recognition of the need to move beyond studies of complex systems that silo social and ecological components (Bodin 2017).

Using the igraph package in the statistical software $\mathrm{R}$ (version 3.2.3), we constructed cognitive maps for each individual fisherman based on the coded interview data. Graph theory provides us with tools to analyze the structure of cognitive maps, and to make comparisons between individual and collective cognitive maps based on a variety of metrics (Özesmi and Özesmi 2004). The metrics we used to represent the structure of ecological knowledge included the number of nodes $(N)$ and edges $(C)$, which together describe the size of the network, network density $(D)$, and a complexity index based on the ratio of receiver to transmitter variables. Network density is an index of connectivity:

$$
D=C /\left[\frac{N}{N-1}\right]
$$

or alternatively,

$$
D=C / N^{2}
$$

if a node can have a causal effect on itself (Hage and Harary 1983, as cited in Özesmi and Özesmi 2004). The typology of network nodes describes how nodes interact with one another. The complexity of the network is the ratio of receiver to transmitter nodes, where transmitter nodes are forcing functions with significant influence over the system and receiver nodes represent the end result of system operation (Stier et al. 2017). A large number of receivers indicates that the cognitive map considers many outcomes of the system, while many transmitter variables indicates a system that includes less elaboration of causal relationships.

To identify potential groupings of fishermen, we subjected the metrics for each fisherman's network to hierarchical clustering analysis (Stier et al. 2017). We also aggregated all of the individual cognitive maps for each of the identified edges to visualize community network structure, and used a network difference function to analyze the contribution of each individual cognitive 
Fig. 1. Multigraph networks representing diverse types of relationships identified by fishermen (purple $=$ species abundance or distribution; blue $=$ species behavior; green $=$ system health; red $=$ food web). $(\mathrm{A}-\mathrm{D})$ Composite networks for each of the four primary types of local ecological knowledge described by all fishermen. Edges and nodes weighted by the number of interviewees that described each relationship. (E) Composite network for all types of ecological knowledge described by all fishermen.
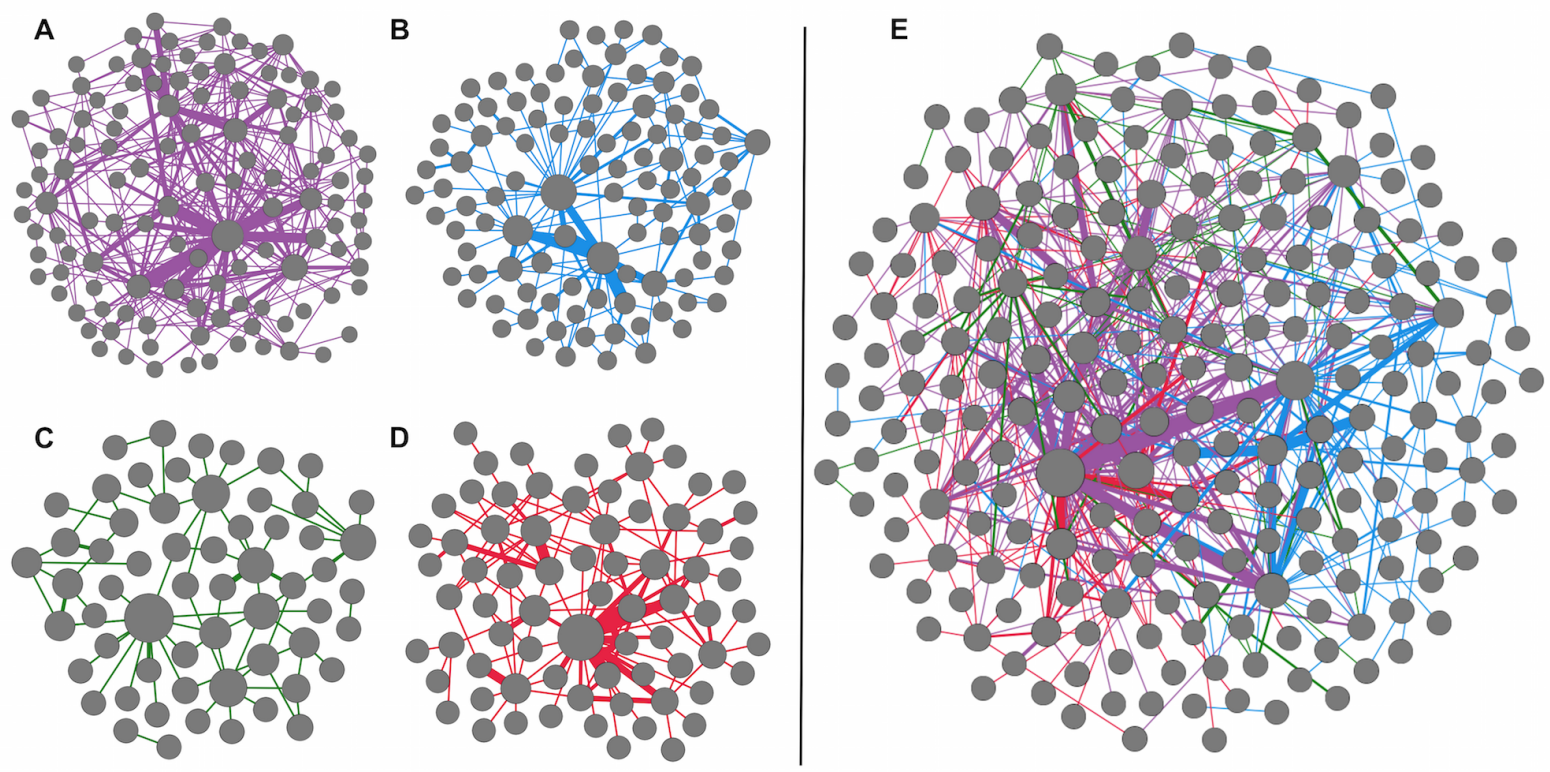

map to the collective ecological knowledge. To link fisheries participation with LEK, we used Ordinary Least Squares Regression testing to identify relationships between participation and the four individual structural metrics used to describe each cognitive map: number of nodes, number of edges, network density, and network complexity.

\section{RESULTS}

Interviewees identified 229 unique biotic and abiotic components of the ecosystem (nodes) and 635 unique relationships between them (edges), discounting repeated edges (Fig. 1). Factors affecting species abundance or distribution were the most common edge type $(n=245)$, followed by those affecting species behavior $(n=249)$ and food web structure $(n=224)$. Drivers of system health were the least common edge $(n=48)$, and were described in reference to only about half of the discussed fisheries. Some relationships are defined by multiple edge types, depending on the nature of the fishermen's description. For example, cod eats lobster (food web) and influences lobster behavior (species behavior).

Each interviewee identified multiple new relationships and components in the environment that had not been articulated by the other fishermen (Fig. 2). Successive subtraction of individual cognitive maps from the composite network revealed a correlation $\left(\mathrm{R}^{2}=0.99\right)$ between the number of interviews and the number of edges. In contrast, after 17 interviews there was some leveling off of new nodes that were identified. These results suggest that we did not reach interview saturation for the edges, but may have been approaching saturation for the nodes.
Fig. 2. Total number of new ecosystem components (nodes) and relationships (edges) contributed by fishermen.

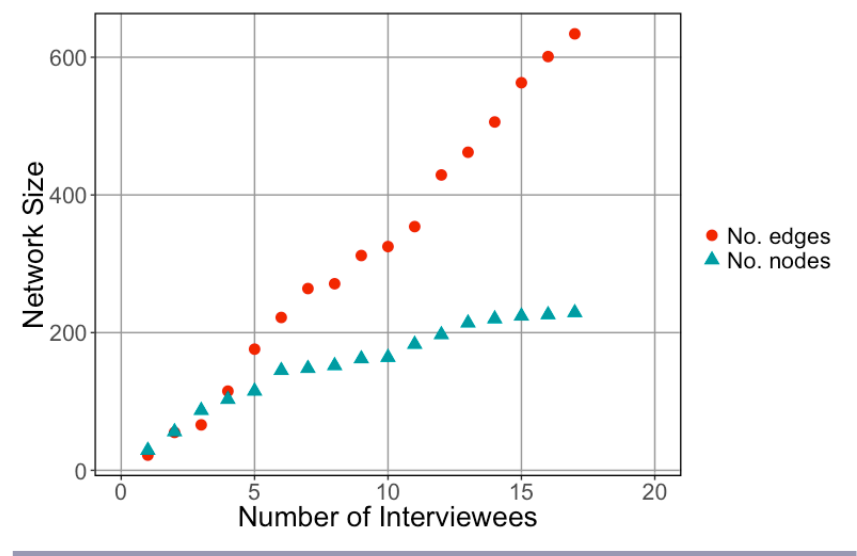

Three significant groups of fishermen were identified by the hierarchical cluster analysis of individual cognitive maps based on four structural network metrics (number of nodes, number of edges, complexity, and density; Fig. 3). Ordinary Least Squares regression testing found a significant positive correlation $(\mathrm{P}<$ 0.01 , adjusted $\mathrm{R}^{2}=0.381$, $\mathrm{df}=15$ ) between the total number of fisheries in which a fisherman has participated, past and present, and their individual network size (number of nodes and edges), including all four edge types (Fig. 4). Fishermen in group 1 (red) have participated in between one and four fisheries and have the smallest networks whereas those in group 2 (blue) have 
participated in between three and nine fisheries and have the largest networks. Ordinary Least Squares regression testing also found a significant positive correlation between the number of fisheries in which an individual has participated and network complexity $\left(\mathrm{P}<0.05\right.$, adjusted $\mathrm{R}^{2}=0.198$, df $\left.=15\right)$, whereby cognitive maps for more diversified fishermen have greater elaboration of causal ecological relationships. No significant relationship exists between length of experience fishing and any network structural metrics: fishermen in group 1 ranged in experience from 20 to 50 years, in group 2 from 18 to 65 years, and in group 3 from 15 to 67 years.

Fig. 3. (A) Hierarchical cluster analysis of individual network maps based on structural metrics, and including all four edge types, revealed three major clusters. Branch distance is proportional to similarity of individual network structure. (B) Network clusters are based on analysis of four network metrics, plotted in box and whisker plots.

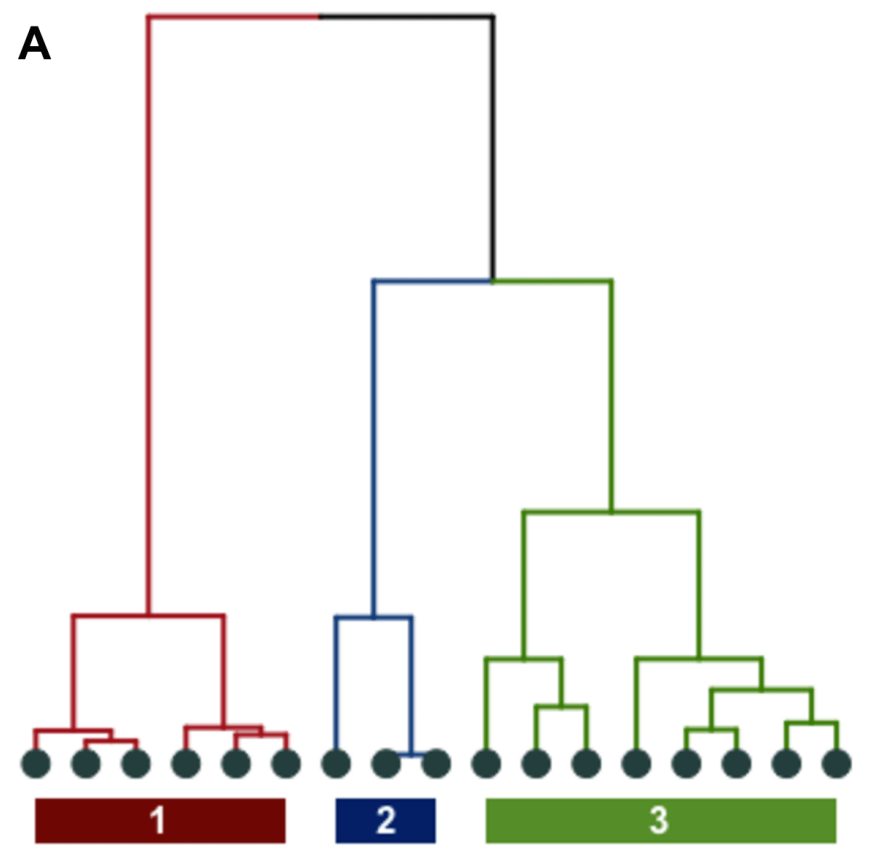

B
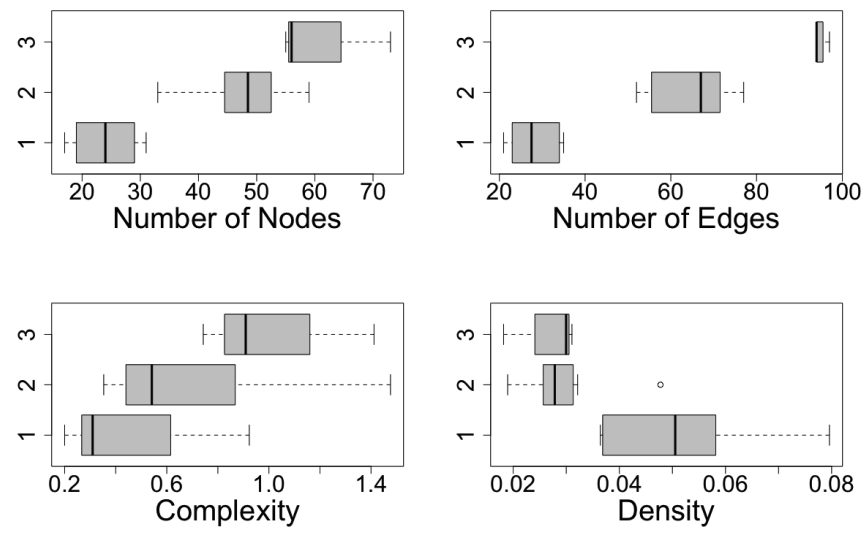

Fig. 4. Number of fisheries in which an individual participates (past and present) is a significant predictor of individual network size.

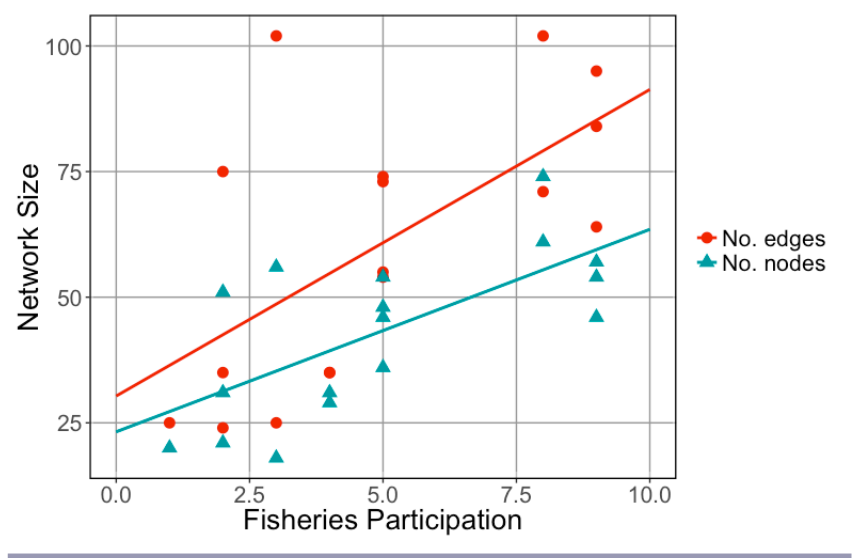

\section{DISCUSSION}

Fishermen are attentive to many ecological parameters that dictate where and when to find their target species, including bottom type, water temperature, feeding interactions, seasonality, and species movement or migration patterns. Their LEK encompasses information at varying scales, from broad climatic dynamics and fish migration patterns to individual species feeding behavior and observed changes in specific coves or on particular mud flats. Such knowledge also tends to be inherently difficult to categorize because observations about one dynamic or ecosystem interaction meld with others. Thus, physical processes are described in close association with ecological processes, which are in turn linked to biological and socioeconomic processes. We can see this multidimensional nature of fishermen's LEK, for example, in the following description of lobster migration patterns (Fig. 5):

When you have the deep sea jellyfish start chasing plankton up in May and June, water columns are getting warmer. When that starts happening, lobsters start migrating north. Another telltale water temperature indicator is when the migratory bird offspring cluster up and start to swim around this island, the lobsters are generally right at the head of the bay.

Although this rich and entangled knowledge appears to be common among fishermen, the particulars of fishermen's knowledge of the marine ecosystem is not homogenous. Rather, we find that knowledge differs among individuals (even among those who are virtually neighbors). The link between knowledge and individual experience seems to be related, in part, to the components of the environment with which fishermen interact on a regular basis. The parts of an ecosystem that a fisherman interacts with depends on numerous factors. Some of these factors are specific to an individual's personal circumstances and include age and health. Economic factors, such as the price of bait or the price lobsters will fetch on the market, also influence fishing behavior, as do ecosystem conditions like the declining biomass of some marine resources. Moreover, fishermen who participate 
in multiple fisheries interact with the environment more broadly than those who are specialized, which allows them to develop a relatively holistic understanding of the ecosystem, including the human dimensions. This multitude of interactions occurs because each fishery involves specific gear, occurs in a particular season, or takes place in a different area. For example, diving for sea urchins exposes a fisherman to a different set of ecosystem components and species interactions than digging for marine worms in the intertidal zone or gill-netting for groundfish offshore. Livelihood diversification has significant implications for the distribution of knowledge.

Fig. 5. Network depicting fisherman's description of indicators of seasonal patterns in the spatial distribution of lobster, and the relationship with spatial distribution of fishing effort, including four types of relationships (purple $=$ species abundance or distribution; blue $=$ species behavior; red $=$ food web; black $=$ socioeconomic).

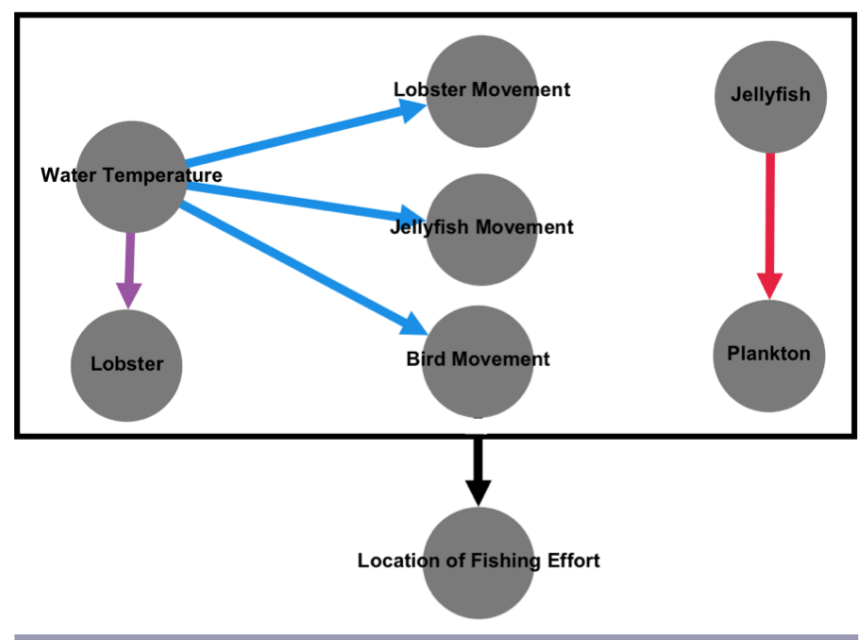

In Maine, a changing policy environment that has increasingly restricted access to fisheries appears to be affecting fishermen's local ecological knowledge. In particular, the state legislature has created a licensing system that has steadily limited the species that fishermen can target. Although decreasing diversification was not ever the intent of the system, fishermen's access to state fisheries has declined over half during the last 25 years and today twothirds of fishermen hold only one license (Stoll et al. 2016, 2017). A changing federal fishery landscape, most notably in the groundfish industry, has also played a role in declining access among Maine fishermen. After a series of efforts to address unsustainable fishing effort and historic lows in groundfish populations, the New England Fishery Management Council adopted a catch share program in 2010 , which allocated quota based on recent catch history. When this occurred, the groundfish industry experienced consolidation, and the number of active vessels declined from over a thousand in the 1990s to 220 in 2015 (Brewer et al. 2017). These concerns are not unique to Maine. Increasingly, fisheries management systems in other contexts have limited access and participation (Carothers 2011, Pinkerton and Davis 2015), influencing the ways in which fishermen interact with various components of the marine environment and in turn shaping the production of LEK.
These findings based on exploratory research merit further investigation with alternative methods and a larger sample size. In particular, we relied on free-flowing conversation based on a semistructured interview guide rather than structured questionnaires, which would have facilitated comparisons across individuals and groups. Furthermore, we did not reach data saturation after 17 interviews. In qualitative analysis, meta themes are expected to emerge after about 10 interviews (Guest et al. 2006). However, as a result of our relatively small sample size and large breadth of information discussed, new observations were added with each successive interview. This is not surprising given the range of fisheries portfolios, geographies, and levels of experience among research participants. It is also possible that the fine-scale nature of the ecosystem, and its dynamism across space and time, makes this knowledge domain particularly variable. Alternative methods to studying the distribution of knowledge, such as cultural consensus analysis using structured questionnaires (Miller et al. 2004, García-Quijano 2006 , Carothers et al. 2014), would provide more explanatory power of drivers of variability. Nevertheless, our findings provide preliminary evidence to suggest that the fisheries management system in Maine may be affecting the production of LEK. Although a more systematic investigation is needed to tease apart potentially confounding variables, these findings have implications that extend to other places where management structures are altering the ways that fishermen are interacting with the marine environment.

\section{CONCLUSION}

Despite the ongoing debate about the relevance of LEK to management, limited attention has been given to the role that management systems play in shaping LEK itself. We posit that greater attention to this inverse relationship may help to explain important differences in LEK among fishermen, which, in turn, ultimately influences the type of information that individuals contribute back to management. Based on a set of in-depth, openended interviews with fishermen in Maine, we see a significant relationship between fishermen's ecological knowledge and the suite of fisheries that they target. Specifically, those with more diversified fishing portfolios appear to have a more comprehensive understanding of the ecosystem than those who are relatively specialized. Although further research is needed to understand the observed correlation, our results suggest that there is a feedback between LEK and management systems, whereby management systems influence the production of LEK, which in turn has implications for the utility of LEK in management. In other words, the potential alteration of LEK by management practices that limit access appears to change the nature of LEK, thereby changing its potential role in understanding marine ecological processes. If this relationship holds true, then understanding the structure of management systems and how they influence the ways fishermen interact with the marine environmental is critical to understanding the potential contributions that LEK can make to management.

Responses to this article can be read online at: http://www.ecologyandsociety.org/issues/responses. php/10344 


\section{Acknowledgments:}

This project would not have been possible without the fishermen who participated in interviews, taking time out of a busy fishing season to share their knowledge with us. Generous funding was provided by the Eastern Maine Conservation Initiative, Maine Center for Coastal Fisheries, the University of Maine, and Maine Sea Grant. We also wish to thank Carla Guenther, Robin Alden, Mike Thalhauser, Patrick Shepard, and Ted Ames for their support establishing connections with members of the fishing industry and their invaluable feedback throughout the process, and Marina Cucuzza for assisting with interviews. Finally, we thank two anonymous reviewers for their thoughtful comments that improved the manuscript.

\section{LITERATURE CITED}

Acheson, J. 2003. Capturing the commons: devising institutions to manage the Maine lobster industry. University Press of New England, Lebanon, New Hampshire, USA.

Ames, E. 2002. Putting fishermen's knowledge to work: the promise and pitfalls. Pages 184-188 in Putting fishers' knowledge to work: conference proceedings August 27-30, 2001. Fisheries Centre, University of British Columbia, Vancouver, British Columbia, Canada.

Ames, E. 2004. Atlantic cod stock structure in the Gulf of Maine. Fisheries 29(1):10-28. http://dx.doi.org/10.1577/1548-8446(2004) 29[10:ACSSIT]2.0.CO;2

Aswani, S., and M. Lauer. 2006. Incorporating fishermen's local knowledge and behavior into geographic information systems (GIS) for designing marine protected areas in Oceania. Human Organization 65(1):81-102. http://dx.doi.org/10.17730/ humo.65.1.4y2q0vhe4130n0uj

Berg, B. L. 2004. Methods for the social sciences. Pearson Education Inc., London, UK.

Berkes, F., J. Colding, and C. Folke. 2000. Rediscovery of traditional ecological knowledge as adaptive management. Ecological Applications 10(5):1251-1262. http://dx.doi. org/10.1890/1051-0761(2000)010[1251:ROTEKA]2.0.CO;2

Bodin, Ö. 2017. Collaborative environmental governance: achieving collective action in social-ecological systems. Science 357(6352). http://dx.doi.org/10.1126/science.aan1114

Brewer, J. F., K. Molton, R. Alden, and C. Guenther. 2017. Accountability, transformative learning, and alternate futures for New England groundfish catch shares. Marine Policy 80:113-122. http://dx.doi.org/10.1016/j.marpol.2016.09.015

Carothers, C. 2011. Equity and access to fishing rights: exploring the community quota program in the Gulf of Alaska. Human Organization 70:213-223. http://dx.doi.org/10.17730/humo.70.3. d686u2r7j2267055

Carothers, C., C. Brown, K. J. Moerlein, J. López, D. B. Andersen, and B. Retherford. 2014. Measuring perceptions of climate change in northern Alaska: pairing ethnography with cultural consensus analysis. Ecology and Society 19(4):27. http://dx.doi. org/10.5751/ES-06913-190427
Casagrande, D. G. 2004. Conceptions of primary forest in a Tzeltal Maya community: implications for conservation. Human Organization 63(2):189-202. http://dx.doi.org/10.17730/humo.63.2. tjtaa6vwkcjaljh7

Colburn, L. L., P. M. Clay, J. Olson, P. Pinto da Silva, S. L. Smith, A. Westwood, and J. Ekstrom. 2010. Community profiles for northeast U.S. marine fisheries. NOAA Fisheries, Northeast Fisheries Science Center, Social Sciences Branch, Woods Hole, Massachusetts, USA.

Crona, B. I. 2006. Supporting and enhancing development of heterogeneous ecological knowledge among resource users in a Kenyan seascape. Ecology and Society 11(1):32. http://dx.doi. org/10.5751/ES-01712-110132

Curtin, C. G., and S. Hammit. 2012. Outcomes of socialecological experiments in near-shore marine environments: cognitive interpretation of the impact of changes in fishing gear type on ecosystem form and function. Pages 457-472 in H. A. Karl, L. Scarlett, J. C. Vargas-Moreno, and M. Flaxman, editors. Restoring lands - coordinating science, politics and action: complexities of climate and governance. Springer Science and Business Media, Dordrecht, The Netherlands. http://dx.doi. org/10.1007/978-94-007-2549-2 21

Finlayson, A. C. 1994. Fishing for truth: a sociological analysis of northern cod stock assessments from 1977 to 1990. Institute of Social and Economic Research, Memorial University of Newfoundland, St. John's, Newfoundland, Canada.

Gagnon, C. A., and D. Berteaux. 2009. Integrating traditional ecological knowledge and ecological science: a question of scale. Ecology and Society 14(2):9. http://dx.doi.org/10.5751/ES-02923-140219

Garavito-Bermúdez, D., C. Lundholm, and B. Crona. 2016. Linking a conceptual framework on systems thinking with experiential knowledge. Environmental Education Research 22 (1):89-110. http://dx.doi.org/10.1080/13504622.2014.936307

García-Quijano, C. G. 2006. Resisting extinction: the value of local ecological knowledge for small-scale fishers in southeastern Puerto Rico. Dissertation. University of Georgia, Athens, Georgia, USA.

García-Quijano, C. G. 2007. Fishers' knowledge of marine species assemblages: bridging between scientific and local ecological knowledge in southeastern Puerto Rico. American Anthropologist 109(3):529-536. http://dx.doi.org/10.1525/aa.2007.109.3.529

García-Quijano, C. G., and M. V. Pizzini. 2015. Ecosystem-based knowledge and reasoning in tropical, multi- species, small-scale fishers' LEK: What can fishers LEK contribute to coastal ecological science and management? Pages 19-40 in J. Fisher, J. Jorgensen, H. Josupeit, D. Kalikoski, and C. M. Lucas, editors. Fishers' knowledge and the ecosystem approach to fisheries. Applications, experiences and lessons in Latin America. FAO Fisheries and Aquaculture, Food and Agriculture Organization, Rome, Italy.

Gray, S., A. Chan, D. Clark, and R. Jordan. 2012. Modeling the integration of stakeholder knowledge in social-ecological decision-making: benefits and limitations to knowledge diversity. Ecological Modelling 229:88-96. http://dx.doi.org/10.1016/j. ecolmodel.2011.09.011 
Guest, G., A. Bunce, and L. Johnson. 2006. How many interviews are enough? An experiment with data saturation and variability. Field Methods 18(1):59-82. http://dx.doi.org/10.1177/1525822X05279903

Hanna, S. 1998. Managing for human and ecological context in the Maine soft shell clam fishery. Pages 190-211 in F. Berkes and C. Folke, editors. Linking social and ecological systems: management practices and social mechanisms for building resilience. Cambridge University Press, Cambridge, UK.

Hmelo-Silver, C. E., and M. G. Pfeffer. 2004. Comparing expert and novice understanding of a complex system from the perspective of structures, behaviors, and functions. Cognitive Science 28:127-138. http://dx.doi.org/10.1207/s15516709cog2801 7

Hollamby, K. L., P. E. McShane, S. Sloan, and J. Brook. 2010. Competition to collaboration: exploring co-management models for the Spencer Gulf Prawn Fishery. FRDC Report 2007/025. Fisheries Research and Development Corporation and the Spencer Gulf and West Coast Prawn Fishermen's Association, Canberra, Australia. [online] URL: http://www.frdc.com.au/ Archived-Reports/FRDC \%20Projects/2007-025-DLD.pdf

Johannes, R. E., M. M. R. Freeman, and R. J. Hamilton. 2000. Ignore fishers' knowledge and miss the boat. Fish and Fisheries 1:257-271. http://dx.doi.org/10.1111/j.1467-2979.2000.00019.x

Miller, M. L., J. Kaneko, P. Bartram, J. Marks, and D. D. Brewer. 2004. Cultural consensus analysis and environmental anthropology: yellowfin tuna fishery management in Hawaii. Cross-Cultural Research 38(3):289-314. http://dx.doi. org/10.1177/1069397104264278

Moller, H., F. Berkes, P. O. Lyver, and M. Kislalioglu. 2004. Combining science and traditional ecological knowledge: monitoring populations for co-management. Ecology and Society 9(3):2. http://dx.doi.org/10.5751/ES-00675-090302

Murray, G., D. Bavington, and B. Neis. 2005. Local ecological knowledge, science, participation and fisheries governance in Newfoundland and Labrador: a complex, contested, and changing relationship. Pages 269-290 in T. S. Gray, editor. Participation in fisheries governance. Springer, Dordrecht, The Netherlands.

Murray, G., B. Neis, and J. P. Johnsen. 2006. Lessons learned from reconstructing interactions between local ecological knowledge, fisheries science, and fisheries management in the commercial fisheries of Newfoundland and Labrador, Canada. Human Ecology 34(4):549-571. http://dx.doi.org/10.1007/s10745-006-9010-8

Nadasdy, P. 1999. The politics of TEK: power and the "integration" of knowledge. Artic Anthropology 36(1):1-18.

Nadasdy, P. 2003. Reevaluating the co-management success story. Arctic 56(4):367-380. http://dx.doi.org/10.14430/arctic634

Olsson, P., and C. Folke. 2001. Local ecological knowledge and institutional dynamics for ecosystem management: a study of Lake Racken Watershed, Sweden. Ecosystems 4:85-104. http://dx. doi.org/10.1007/s100210000061

Ommer, R. E., R. I. Perry, G. Murray, and B. Neis. 2012. Socialecological dynamism, knowledge, and sustainable coastal marine fisheries. Current Opinion in Environmental Sustainability 4:316-322. http://dx.doi.org/10.1016/j.cosust.2012.05.010

Özesmi, U., and S. L. Özesmi. 2004. Ecological models based on people's knowledge: a multi-step fuzzy cognitive mapping approach. Ecological Modelling 176:43-64. http://dx.doi. org/10.1016/j.ecolmodel.2003.10.027

Paolisso, M. 2002. Blue crabs and controversy on the Chesapeake Bay: a cultural model for understanding watermen's reasoning about blue crab management. Human Organization 61 (3):226-239. http://dx.doi.org/10.17730/humo.61.3.2dc5c4gxap2f6nwv

Pauly, D. 1995. Anecdotes and the shifting baseline syndrome of fisheries. Trends in Ecology and Evolution 10(10):430. http://dx. doi.org/10.1016/S0169-5347(00)89171-5

Pikitch, E. K., C. Santora, E. A. Babcock, A. Bakun, R. Bonfil, D. O. Conover, P. Dayton, P. Doukakis, D. Fluharty, B. Heneman, E. D. Houde, J. Link, P. A. Livingston, M. Mangel, M. K. McAllister, J. Pope, and K. J. Sainsbury. 2004. Ecosystem-based fishery management. Science 305:346-347. http://dx.doi. org/10.1126/science. 1098222

Pinkerton, E., and R. Davis. 2015. Neoliberalism and the politics of enclosure in North American small-scale fisheries. Marine Policy 61:303-312. http://dx.doi.org/10.1016/j.marpol.2015.03.025

Ruddle, K. 1994. Local knowledge in the folk management of fisheries and coastal marine environments. Pages 161-206 in C. L. Dyer and J. R. McGoodwin, editors. Folk management in the world's fisheries: lessons for modern fisheries management. University Press of Colorado, Niwot, CO.

Shafie, T. 2015. A multigraph approach to social network analysis. Journal of Social Structure 16.

Silvano, R. A. M., and J. Valbo-Jørgensen. 2008. Beyond fishermen's tales: contributions of fishers' local ecological knowledge to fish ecology and fisheries management. Environment, Development and Sustainability 10(5):657-675. http://dx.doi.org/10.1007/s10668-008-9149-0

Stier, A. C., J. F. Samhouri, S. Gray, R. G. Martone, M. E. Mach, B. S. Halpern, C. V. Kappel, C. Scarborough, and P. S. Levin. 2017. Integrating expert perceptions into food web conservation and management. Conservation Letters 10(1):67-76. http://dx.doi. org/10.1111/conl.12245

Stoll, J. S. 2017. Fishing for leadership: the role diversification plays in facilitating change agents. Journal of Environmental Management 199:74-82. http://dx.doi.org/10.1016/j.jenvman.2017.05.011

Stoll, J. S., C. M. Beitl, and J. A. Wilson. 2016. How access to Maine's fisheries has changed over a quarter century: the cumulative effects of licensing on resilience. Global Environmental Change 37:79-91. http://dx.doi.org/10.1016/j.gloenvcha.2016.01.005

Stoll, J. S., E. Fuller, and B. I. Crona. 2017. Uneven adaptive capacity among fishers in a sea of change. PLoS ONE 12(6): e0178266. http://dx.doi.org/10.1371/journal.pone.0178266

Walsh, F. J., P. V. Dobson, and J. C. Douglas. 2013. Anpernirrentye: a framework for enhanced application of 
indigenous ecological knowledge in natural resource management. Ecology and Society 18(3):18. http://dx.doi. org/10.5751/ES-05501-180318

Wohling, M. 2009. The problem of scale in indigenous knowledge: a perspective from northern Australia. Ecology and Society 14 (1):1. http://dx.doi.org/10.5751/ES-02574-140101

Wondolleck, J. M., and S. L. Yaffee. 2017. Marine ecosystem-based management in practice: different pathways, common lessons. Island, Washington, D.C., USA. http://dx.doi.org/10.5822/978-1-61091-800-8 